\title{
PENGGUNAAN HERBISIDA AMONIUM GLUFOSINAT PADA PERSIAPAN LAHAN PADI SAWAH (Oryza sativa L.) DENGAN SISTEM TANPA OLAH TANAH
}

\author{
Cindy Felixia, Dad R. J. Sembodo \& Kuswanta F. Hidayat \\ Jurusan Agroteknologi Fakultas Pertanian Universitas Lampung \\ Jl. Sumantri Brojonegoro No 1 Bandar Lampung \\ E-mail: cindyfelixia94@gmail.com
}

\begin{abstract}
ABSTRAK
Penelitian ini bertujuan untuk mengetahui efektivitas herbisida amonium glufosinat dalam mengendalikan gulma pada persiapan lahan padi sawah dengan sistem tanpa olah tanah (TOT) serta mengetahui pengaruh sistem TOT terhadap produksi padi sawah. Penelitian ini dilaksanakan di Desa Tempuran, Kecamatan Trimurjo, Kabupaten Lampung Tengah dan di Laboratorium Ilmu Gulma, Jurusan Agroteknologi, Fakultas Pertanian, Universitas Lampung mulai bulan Januari 2016 sampai April 2016 dengan menggunakan Rancangan Acak Kelompok (RAK) dengan 4 perlakuan dosis herbisida amonium glufosinat (480, 640, 800, dan $960 \mathrm{~g} / \mathrm{ha}$ ) dengan sistem TOT, penyiangan secara mekanis dengan sistem OTS, dan kontrol (tanpa pengendalian gulma dengan sitem TOT) dan diulang sebanyak 4 ulangan. Homogenitas ragam diuji dengan menggunakan Uji Barttlet dan additifitas data diuji menggunakan Uji Tukey. Jika asumsi terpenuhi maka data dianalisis dengan sidik ragam dengan menggunakan pemisahan nilai tengah Beda Nyata Terkecil (BNT) pada taraf 5\%. Hasil penelitian menunjukkan bahwa semua taraf dosis herbisida amonium glufosinat yang diuji (480-960 g/ha) dan penyiangan mekanis mampu mengendalikan gulma total dan gulma golongan rumput hingga 7 minggu setelah aplikasi (MSA), sedangkan gulma golongan daun lebar dan golongan rumput mampu dikendalikan oleh herbisida amonium glufosinat dan penyiangan mekanis hingga 7 MSA pada taraf dosis 640-960 g/ha, namun gulma golongan teki terutama Fimbristilys miliacea serta gulma Leptochloa chinensis tidak mampu dikendalikan oleh herbisida ini. Hasil gabah kering giling pada sistem TOT lebih rendah dibandingkan dengan hasil gabah kering giling jika pada sistem OTS.
\end{abstract}

Kata kunci: amonium glufosinat, gulma, padi, TOT.

\section{PENDAHULUAN}

Produksi padi selama periode tahun 2008-2013 meningkat dari 60,325 juta ton gabah kering giling (GKG) pada tahun 2008 menjadi 71,291 juta ton GKG pada tahun 2013 atau rata-rata tumbuh 3,43\% atau sebesar 2,193 juta ton per tahun. Namun jika dibandingkan dengan target produksi tahun 2013, produksi padi belum mencapai target disebabkan karena belum optimalnya peningkatan produktivitas dari target $52 \mathrm{ku} / \mathrm{ha}$ (Ditjen TP, 2014). Faktor-faktor yang menyebabkan rendahnya hasil padi baik kualitas dan kuantitas antara lain adalah degradasi lahan dan gangguan gulma. Diantara sekian banyak penyebab degradasi lahan, yang paling dominan adalah erosi tanah dan air. Erosi tanah di daerah tropika basah termasuk Indonesia sebagian besar disebabkan oleh pengolahan tanah intensif (OTI) yang secara turun temurun masih terus dilakukan oleh petani. Teknik olah tanah konservasi (OTK) yang dapat diterapkan antara lain adalah tanpa olah tanah (TOT) (Utomo, 2002). Selain degradasi lahan, gulma sebagai organisme pengganggu tanaman (OPT) termasuk kendala penting yang harus diatasi dalam peningkatan produksi padi di Indonesia. Gulma merupakan salah satu faktor pembatas produksi tanaman padi, karena gulma dapat menyerap hara dan air lebih cepat dibanding tanaman pokok (Gupta, 1984). Kehilangan hasil padi sawah akibat gulma diperkirakan mencapai 30\% (Suardi dan Pane, 1983). Tanpa tindakan pengendalian gulma, kehilangan hasil diperkirakan mencapai 16\% hingga 86\% (Kropff dan van Laar, 1993).

Penggunaan herbisida tidak dapat dipisahkan dalam penyiapan lahan sistem TOT. Persiapan lahan cukup dilakukan dengan penyemprotan, setelah gulma mulai mati dan mengering, dan dibiarkan agar permukaan tanah tertutupi guna mengurangi evaporasi, melindungi kehidupan organisme tanah, dan mepertahankan kandungan unsur hara tanah (Rafiuddin et al, 2006). Herbisida berbahan aktif amonium glufosinat merupakan herbisida yang direkomendasikan untuk mengendalikan gulma karena herbisida amonium glufosinat merupakan herbisida nonselektif dan kontak yang diaplikasikan 
pasca tumbuh. Keuntungan penggunaan herbisida kontak adalah gulma cepat mati sehingga dapat segera ditanami. Namun herbisida amonium glufosinat belum banyak digunakan untuk pengendalian gulma pada persiapan lahan padi sawah dengan sistem TOT, maka penelitian ini dilakukan untuk mengetahui keefektivan amonium glufosinat dalam mengendalikan gulma pada persiapan lahan pertanaman padi tanpa olah tanah (TOT).

\section{BAHAN DAN METODE}

Penelitian dilaksanakan di Desa Tempuran, Kecamatan Trimurjo, Kabupaten Lampung Tengah dan di Laboratorium Ilmu Gulma, Jurusan Agroteknologi, Fakultas Pertanian, Universitas Lampung mulai bulan Januari 2016 sampai bulan April 2016. Bahan-bahan yang digunakan dalam penelitian ini adalah herbisida dengan bahan aktif amonium glufosinat (Admil 160 SL), air, pupuk Urea, $\mathrm{KCl}$, dan SP-36, serta benih padi varietas Ciherang. Alat-alat yang digunakan adalah meteran, timbangan digital, tali rafia, alat semprot punggung, nozel T-jet warna biru, bambu, ember, plastik, gelas ukur, oven, pipet, amplop kertas, alat tulis, dan perlengkapan lainnya.

Penelitian menggunakan Rancangan Acak Kelompok (RAK) dengan empat perlakuan herbisida $(480,640,800,960 \mathrm{~g} / \mathrm{ha})$ dengan sistem tanpa olah tanah (TOT), penyiangan mekanis dengan sistem olah tanah sempurna (OTS), dan kontrol dengan 4 ulangan. Untuk menilai pengaruh penggunaan herbisida terhadap pertumbuhan gulma digunakan perlakuan kontrol. Sebagai pembanding yang digunakan untuk melihat pengaruh herbisida terhadap tanaman padi sawah adalah pengendalian gulma secara mekanis dengan pengolahan tanah sempurna (OTS). Homogenitas ragam diuji dengan menggunakan Uji Barttlet dan additifitas data diuji menggunakan Uji Tukey. Jika asumsi terpenuhi maka data dianalisis dengan sidik ragam dengan menggunakan pemisahan nilai tengah Beda Nyata Terkecil (BNT) pada taraf 5\%.

Persiapan Lahan dan Aplikasi Herbisida. Petak percobaan TOT dikeringkan dengan cara membuka saluran air keluar dan menutup saluran air masuk. Sebelum aplikasi dilakukan, alat semprot punggung dikalibrasi terlebih dahulu menggunakan metode luas sehingga diperoleh volume semprot nya yaitu $467 \mathrm{~L} / \mathrm{ha}$. Tiga hari setelah aplikasi herbisida, air kembali dimasukkan hingga plot tergenang dengan ketinggian 2-5 cm dan dibiarkan selama empat hari sampai tanah menjadi lunak.

Penanaman dan Pemuukan. Penanaman dilakukan satu minggu setelah aplikasi (MSA), menggunakan bibit umur 21 hari. Jarak tanam yang diterapkan adalah $25 \times 25 \mathrm{~cm}$ dengan dua bibit per lubang tanam.Pemupukan dilakukan 2 kali dengan cara disebar. Pemupukan pertama pada 7 hari setelah tanam (HST) dengan dosis Urea $100 \mathrm{~kg} / \mathrm{ha}, \mathrm{SP}-36150 \mathrm{~kg} / \mathrm{ha}$, dan $\mathrm{KCl} 100 \mathrm{~kg} / \mathrm{ha}$. Pemupukan kedua dilakukan saat primordia bunga dengan dosis Urea $100 \mathrm{~kg} / \mathrm{ha}$.

Pengambilan Sampel Gulma. Pengambilan sampel gulma dilakukan 3 kali yaitu pada 1, 4, dan 7 (MSA) bersamaan dengan pelaksanaan penyiangan gulma secara mekanis. Pada setiap pengamatan diambil contoh gulma dalam 2 petak contoh yang diletakan secara sistematis, berukuran $0,5 \times 0,5 \mathrm{~m}$.

\section{HASIL DAN PEMBAHASAN}

Data bobot kering gulma total yang disajikan pada Tabel 1 menunjukan bahwa herbisida amonium glufosinat dengan berbagai taraf dosis efektif dalam mengendalikan

Tabel 1. Bobot Kering Gulma Total

\begin{tabular}{|c|c|c|c|}
\hline Perlakuan & $1 \mathrm{MSA}$ & 4 MSA & 7 MSA \\
\hline & \multicolumn{3}{|c|}{$\ldots \ldots \ldots \ldots \ldots \ldots \ldots \ldots\left(\mathrm{g} / 0,5 \mathrm{~m}^{2}\right) \ldots \ldots \ldots \ldots \ldots \ldots$} \\
\hline Amonium glufosinat $480 \mathrm{~g}+\mathrm{TOT}$ & $57,16 \mathrm{~b}$ & $80,70 \quad b$ & $172,95 \mathrm{~b}$ \\
\hline Amonium glufosinat $640 \mathrm{~g}+\mathrm{TOT}$ & 44,23 bc & $31,76 \mathrm{c}$ & $121,13 \mathrm{c}$ \\
\hline Amonium glufosinat $800 \mathrm{~g}+\mathrm{TOT}$ & $24,34 \mathrm{~d}$ & $27,43 \mathrm{c}$ & $91,39 \mathrm{~cd}$ \\
\hline Amonium glufosinat $960 \mathrm{~g}+\mathrm{TOT}$ & $35,38 \mathrm{~cd}$ & $12,83 \mathrm{c}$ & 66,17 \\
\hline Mekanis + OTS & $0,00 \quad \mathrm{e}$ & $2,51 \quad \mathrm{c}$ & $0,00 \quad \mathrm{e}$ \\
\hline Kontrol & $108,82 \mathrm{a}$ & 198,40 a & 275,41 a \\
\hline BNT 0,05 & 17,55 & 42,07 & 48,54 \\
\hline
\end{tabular}

Keterangan: Nilai tengah pada setiap kolom yang diikuti huruf yang sama tidak berbeda nyata menurut uji BNT pada taraf 5\% 
gulma total sampai 7 minggu setelah aplikasi (MSA). Kemampuan terbaik herbisida amonium glufosinat dalam mengendalikan gulma total pada 1 MSA yaitu pada dosis $800 \mathrm{~g} / \mathrm{ha}$. Pada 4 MSA seluruh taraf dosis herbisida amonium glufosinat yang diuji dapat mengendalikan pertumbuhan gulma. Kondisi gulma yang awalnya terkendali dengan baik pada semua taraf dosis pada 4 MSA, sudah mengalami pertumbuhan kembali pada 7 MSA sehingga perlakuan penyiangan mekanis memberikan hasil pengendalian terbaik.

Spesies gulma golongan daun lebar yang ditemukan pada petak percobaan adalah Melochia corchorifolia, Ludwigia hyssopifolia, Scoparia dulcis, dan Phylantus urinaria. Tabel 2 menunjukkan bahwa herbisida amonium glufosinat pada dosis $480 \mathrm{~g} /$ ha hanya mampu mengendalikan gulma hingga 4 MSA, sedangkan dosis 640-960 g/ha mampu mengendalikan gulma hingga 7 MSA. Hal ini dikarenakan pada dosis ini herbisida amonium glufosinat ada pada dosis terbaik
(0,6-1 kg/ha) dalam mengendalikan gulma (Perkins, 1990).

Spesies gulma golongan teki yang muncul pada petak percobaan adalah Fimbristilys miliacea dan Cyperus iria. Hasil penelitian yang disajikan pada Tabel 3 menunjukkan bahwa herbisida amonium glufosinat dosis $960 \mathrm{~g} / \mathrm{ha}$ dengan sistem TOT mampu mengendalikan gulma golongan teki pada 4 MSA, sedangkan pada 1 MSA dan 7 MSA herbisida amonium glufosinat dengan berbagai taraf dosis yang diujikan tidak mampu mengendalikan gulma golongan teki. Pengendalian secara mekanis dengan sistem OTS memberikan hasil yang terbaik. Hal ini sesuai dengan pernyataan Tjitrosoedirjo, et al. (1984) bahwa pengendalian gulma dengan cara mekanis umumnya dapat berhasil dengan baik dalam mengendalikan gulma semusim serta gulma tahunan.

Terdapat 6 jenis gulma golongan rumput yang ditemukan pada petak percobaan yaitu Leptochloa

Tabel 2. Bobot Kering Gulma Golongan Daun Lebar

\begin{tabular}{|c|c|c|c|}
\hline Perlakuan & $1 \mathrm{MSA}$ & 4 MSA & $7 \mathrm{MSA}$ \\
\hline & \multicolumn{3}{|c|}{$\ldots \ldots \ldots \ldots \ldots \ldots \ldots\left(\mathrm{g} / 0,5 \mathrm{~m}^{2}\right)}$. \\
\hline Amonium glufosinat $480 \mathrm{~g}+\mathrm{TOT}$ & $24,23 \mathrm{~b}$ & $29,12 \mathrm{~b}$ & $66,51 \mathrm{a}$ \\
\hline Amonium glufosinat $640 \mathrm{~g}+\mathrm{TOT}$ & $19,75 \mathrm{~b}$ & $12,69 \mathrm{bc}$ & $24,84 \mathrm{~b}$ \\
\hline Amonium glufosinat $800 \mathrm{~g}+\mathrm{TOT}$ & $6,99 \mathrm{~cd}$ & 6,12 bc & $19,77 \mathrm{~b}$ \\
\hline Amonium glufosinat $960 \mathrm{~g}+\mathrm{TOT}$ & $19,04 \mathrm{bc}$ & 4,58 & $16,63 \mathrm{bc}$ \\
\hline Mekanis + OTS & $0,00 \mathrm{~d}$ & $0,00 \quad \mathrm{c}$ & $0,00 \mathrm{c}$ \\
\hline Kontrol & 48,33 a & $104,95 \mathrm{a}$ & 82,60 a \\
\hline BNT 0,05 & 12,10 & 26,25 & 19,35 \\
\hline
\end{tabular}

Keterangan: Nilai tengah pada setiap kolom yang diikuti huruf yang sama tidak berbeda nyata menurut uji BNT pada taraf $5 \%$

Tabel 3. Bobot Kering Gulma Golongan Teki

\begin{tabular}{|c|c|c|c|}
\hline Perlakuan & $1 \mathrm{MSA}$ & $4 \mathrm{MSA}$ & 7 MSA \\
\hline & \multicolumn{3}{|c|}{$\ldots \ldots \ldots \ldots \ldots \ldots \ldots\left(\mathrm{g} / 0,5 \mathrm{~m}^{2}\right) \ldots \ldots \ldots \ldots \ldots \ldots \ldots$} \\
\hline Amonium glufosinat $480 \mathrm{~g}+\mathrm{TOT}$ & 9,63 a & $20,32 \mathrm{a}$ & $22,53 \mathrm{~b}$ \\
\hline Amonium glufosinat $640 \mathrm{~g}+\mathrm{TOT}$ & $4,59 \mathrm{ab}$ & $6,08 \mathrm{bc}$ & $30,20 \mathrm{ab}$ \\
\hline Amonium glufosinat $800 \mathrm{~g}+\mathrm{TOT}$ & $4,30 \mathrm{ab}$ & 7,97 abc & 42,16 a \\
\hline Amonium glufosinat $960 \mathrm{~g}+\mathrm{TOT}$ & 7,18 a & $1,97 \mathrm{c}$ & $32,77 \mathrm{ab}$ \\
\hline Mekanis + OTS & $0,00 \mathrm{~b}$ & $0,00 \mathrm{c}$ & $0,00 \mathrm{c}$ \\
\hline Kontrol & 7,08 a & $15,63 \mathrm{ab}$ & $16,01 \mathrm{bc}$ \\
\hline BNT 0,05 & 6,98 & 13,24 & 17,42 \\
\hline
\end{tabular}

Keterangan: Nilai tengah pada setiap kolom yang diikuti huruf yang sama tidak berbeda nyata menurut uji BNT pada taraf $5 \%$ 
chinensis, Ischaemum rugosum, Cynodon dactylon , Paspalum commersonii, Digitaria ciliaris, dan Echinochloa colona. Data bobot kering yang disajikan pada Tabel 4 menunjukkan bahwa seluruh taraf dosis yang diuji dengan sistem TOT mampu mengendalikan gulma golongan rumput. Kemampuan seluruh taraf dosis herbisida amonium glufosinat dalam mengendalikan gulma golongan rumput pada 1 MSA sama. Pada 4 MSA dan 7 MSA herbisida amonium glufosinat dengan dosis $800 \mathrm{~g} / \mathrm{ha}$ adalah yang paling efektif dalam mengendalikan gulma golongan rumput karena daya kendali nya sama dengan perlakuan penyiangan mekanis dengan sistem OTS.

M. corchorifolia merupakan gulma paling dominan yang ditemukan pada semua petak percobaan. Berdasarkan data yang disajikan pada Tabel 5 dapat diketahui bahwa herbisida amonium glufosinat dosis 480$960 \mathrm{~g} / \mathrm{ha}$ dengan sistem TOT mampu mengendalikan gulma ini hingga 4 MSA. Pada 7 MSA herbisida amonium glufosinat mampu mengendalikan gulma ini pada dosis 640-960 g/ha. Efektifitas herbisida amonium glufosinat dalam mengendalikan gulma $M$. corchorifolia diduga karena gulma ini merupakan gulma daun lebar yang mempunyai permukaan daun yang luas sehingga droplet herbisida yang diaplikasikan dapat terserap dengan baik dan merata. Menurut Sembodo (2010) dan Moenandir (2010) selektivitas herbisida dapat berkaitan dengan faktor morfologi gulma tersebut.

Bobot kering gulma $F$. miliacea perlakuan herbisisda amonium glufosinat dengan sistem TOT pada berbagai taraf dosis pada 1 MSA tidak berbeda nyata dengan kontrol. Pada 4 MSA bobot kering gulma ini pada dosis $480 \mathrm{~g} /$ ha lebih tinggi dibandingkan dengan kontrol dan perlakuan herbisida amonium glufosinat dosis lainnya, sedangkan herbisida amonium glufosinat dosis 640-960 g/ha juga tidak berbeda nyata dengan kontrol. Perbedaan bobot kering gulma $F$. miliacea mulai terlihat berbeda nyata pada 7 MSA (Tabel 6). Hal ini diduga

Tabel 4. Bobot Kering Gulma Golongan Rumput

\begin{tabular}{|c|c|c|c|}
\hline Perlakuan & $1 \mathrm{MSA}$ & $4 \mathrm{MSA}$ & $7 \mathrm{MSA}$ \\
\hline & \multicolumn{3}{|c|}{$\ldots \ldots \ldots \ldots \ldots \ldots\left(\mathrm{g} / 0,5 \mathrm{~m}^{2}\right)$} \\
\hline Amonium glufosinat $480 \mathrm{~g}+\mathrm{TOT}$ & $23,31 \mathrm{~b}$ & $31,26 \mathrm{~b}$ & $83,92 \mathrm{~b}$ \\
\hline Amonium glufosinat $640 \mathrm{~g}+\mathrm{TOT}$ & $19,89 \mathrm{bc}$ & $12,99 \mathrm{bc}$ & $66,09 \mathrm{bc}$ \\
\hline Amonium glufosinat $800 \mathrm{~g}+\mathrm{TOT}$ & $13,05 \mathrm{bc}$ & $8,82 \mathrm{c}$ & $29,46 \mathrm{cc}$ \\
\hline Amonium glufosinat $960 \mathrm{~g}+\mathrm{TOT}$ & $9,16 \mathrm{~cd}$ & $6,29 \mathrm{c}$ & $16,77 \mathrm{~d}$ \\
\hline Mekanis + OTS & $0,00 \quad d$ & $2,51 \mathrm{c}$ & $0,00 \quad \mathrm{~d}$ \\
\hline Kontrol & 53,41 a & 77,82 a & $176,80 \mathrm{a}$ \\
\hline BNT 0,05 & 11,05 & 18,76 & 46,15 \\
\hline
\end{tabular}

Keterangan: Nilai tengah pada setiap kolom yang diikuti huruf yang sama tidak berbeda nyata menurut uji BNT pada taraf 5\%

Tabel 5. Bobot Kering Gulma M. corchorifolia

\begin{tabular}{|c|c|c|c|}
\hline Perlakuan & $1 \mathrm{MSA}$ & $4 \mathrm{MSA}$ & $7 \mathrm{MSA}$ \\
\hline & \multicolumn{3}{|c|}{ 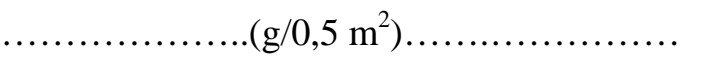 } \\
\hline Amonium glufosinat $480 \mathrm{~g}+\mathrm{TOT}$ & $24,23 \mathrm{~b}$ & $29,12 \mathrm{~b}$ & $65,34 \mathrm{a}$ \\
\hline Amonium glufosinat $640 \mathrm{~g}+\mathrm{TOT}$ & $19,75 \mathrm{~b}$ & $12,69 \mathrm{bc}$ & $23,70 \mathrm{~b}$ \\
\hline Amonium glufosinat $800 \mathrm{~g}+\mathrm{TOT}$ & $6,99 \mathrm{~cd}$ & 6,12 bc & $19,46 \mathrm{~b}$ \\
\hline Amonium glufosinat $960 \mathrm{~g}+\mathrm{TOT}$ & $19,04 \mathrm{bc}$ & 4,58 & $16,63 \mathrm{bc}$ \\
\hline Mekanis + OTS & $0,00 \quad \mathrm{~d}$ & $0,00 \quad c$ & $0,00 \quad \mathrm{c}$ \\
\hline Kontrol & 48,33 a & $104,72 \mathrm{a}$ & 82,46 a \\
\hline BNT 0,05 & 12,01 & 26,15 & 19,25 \\
\hline
\end{tabular}

Keterangan: Nilai tengah pada setiap kolom yang diikuti huruf yang sama tidak berbeda nyata menurut uji BNT pada taraf 5\% 
Tabel 6. Bobot Kering Gulma F. miliacea

\begin{tabular}{|c|c|c|c|}
\hline \multirow{2}{*}{ Perlakuan } & $1 \mathrm{MSA}$ & 4 MSA & $7 \mathrm{MSA}$ \\
\hline & Asli & Asli & Asli \\
\hline & \multicolumn{3}{|c|}{$\ldots \ldots \ldots \ldots \ldots \ldots\left(\mathrm{g} / 0,5 \mathrm{~m}^{2}\right) \ldots \ldots \ldots \ldots \ldots \ldots \ldots$} \\
\hline Amonium glufosinat $480 \mathrm{~g}+\mathrm{TOT}$ & 4,48 a & 20,08 a & $22,53 \mathrm{bc}$ \\
\hline Amonium glufosinat $640 \mathrm{~g}+\mathrm{TOT}$ & $1,05 \mathrm{ab}$ & $6,08 \quad b$ & $29,87 \mathrm{ab}$ \\
\hline Amonium glufosinat $800 \mathrm{~g}+\mathrm{TOT}$ & $0,41 \mathrm{~b}$ & 7,97 & $42,16 \mathrm{a}$ \\
\hline Amonium glufosinat $960 \mathrm{~g}+\mathrm{TOT}$ & $0,43 \mathrm{~b}$ & 1,97 & $32,77 \mathrm{ab}$ \\
\hline Mekanis + OTS & $0,00 \mathrm{~b}$ & 0,00 & $0,00 \mathrm{~d}$ \\
\hline Kontrol & $1,94 a b$ & $8,09 \quad b$ & $10,64 \mathrm{~cd}$ \\
\hline BNT 0,05 & 3,99 & 11,51 & 16,96 \\
\hline
\end{tabular}

Keterangan: Nilai tengah pada setiap kolom yang diikuti huruf yang sama tidak berbeda nyata menurut uji BNT pada taraf $5 \%$

Tabel 7. Bobot Kering Gulma L. chinensis

\begin{tabular}{|c|c|c|c|}
\hline \multirow{2}{*}{ Perlakuan } & $1 \mathrm{MSA}$ & 4 MSA & $7 \mathrm{MSA}$ \\
\hline & Asli & Asli & Asli \\
\hline & \multicolumn{3}{|c|}{ 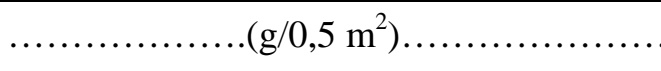 } \\
\hline Amonium glufosinat $480 \mathrm{~g}+\mathrm{TOT}$ & $2,93 \mathrm{a}$ & $11,06 \mathrm{a}$ & $22,61 \mathrm{~b}$ \\
\hline Amonium glufosinat $640 \mathrm{~g}+\mathrm{TOT}$ & 0,98 abc & $6,42 \mathrm{ab}$ & 57,16 a \\
\hline Amonium glufosinat $800 \mathrm{~g}+\mathrm{TOT}$ & $0,90 \mathrm{bc}$ & $6,30 \quad a b$ & $22,86 \mathrm{~b}$ \\
\hline Amonium glufosinat $960 \mathrm{~g}+\mathrm{TOT}$ & $0,65 \mathrm{bc}$ & 3,92 bc & $14,94 \mathrm{~b}$ \\
\hline Mekanis + OTS & $0,00 \mathrm{c}$ & $0,00 \quad \mathrm{c}$ & $0,00 \quad b$ \\
\hline Kontrol & $2,40 \mathrm{ab}$ & $8,28 \mathrm{ab}$ & $18,00 \mathrm{~b}$ \\
\hline BNT 0,05 & 2,03 & 5,87 & 23,13 \\
\hline
\end{tabular}

Keterangan: Nilai tengah pada setiap kolom yang diikuti huruf yang sama tidak berbeda nyata menurut uji BNT pada taraf 5\%

karena saat gulma lain yang kontak dengan herbisida dapat terkendali dengan baik pada 4 MSA menghasilkan kondisi yang menguntungkan bagi biji-biji gulma $F$. miliacea untuk tumbuh sehingga pertumbuhannya semakin tidak terkendali.

Data bobot kering gulma $L$. chinensis pada Tabel 7 menunjukkan bahwa herbisida amonium glufosinat dosis 480-960 g/ha tidak mampu mengendalikan gulma ini baik pada 1 MSA, 4 MSA, maupun 7 MSA. $L$. chinensis merupakan gulma golongan rumput yang memiliki daun yang sempit dan tegak sehingga hanya menerima sedikit droplet herbisida yang menyebabkan herbisida amonium glufosinat tidak mampu mengendalikan gulma ini.

Data bobot kering gulma $I$. rugosum yang disajikan pada Tabel 8 menunjukkan bahwa pada 1 MSA herbisida amonium glufosinat berbagai taraf dosis yang diuji belum mampu mengendalikan gulma I. rugosum pada pertanaman padi dengan sistem TOT. Ketidakmampuan herbisida amonium glufosinat dalam mengendalikan gulma ini pada 1 MSA dikarenakan morfologi gulma. Menurut Tjitrosoerdirjo et al. (1984), daun yang sempit (rerumputan) dan daun yang tegak hanya menerima sedikit droplet sehingga herbisida amonium glufosinat kurang efektif mengendalikan gulma ini. Pada 4 MSA dan 7 MSA herbisida amonium glufosinat dosis 640"960 g/ha mampu mengendalikan gulma Ischaemum rugosum bahkan memiliki daya kendali yang sama dengan perlakuan mekanis dengan sistem OTS.

Perlakuan mekanis dengan sistem OTS pada 1 MSA memberikan hasil terbaik dalam megendalikan gulma total (Tabel 1). Pada 4 MSA perlakuan mekanis dengan sistem OTS memiliki daya kendali yang sama dengan perlakuan herbisida amonium glufosinat dosis 640-960 g/ha (Tabel 1, Tabel 2, Tabel 3, Tabel 4, Tabel 
Tabel 8. Bobot Kering Gulma I. Rugosum

\begin{tabular}{|c|c|c|c|}
\hline \multirow{2}{*}{ Perlakuan } & $1 \mathrm{MSA}$ & 4 MSA & $7 \mathrm{MS} A$ \\
\hline & Asli & Asli & Asli \\
\hline & \multicolumn{3}{|c|}{$\ldots \ldots \ldots \ldots \ldots \ldots \ldots\left(\mathrm{g} / 0,5 \mathrm{~m}^{2}\right) \ldots \ldots \ldots \ldots \ldots \ldots$} \\
\hline Amonium glufosinat $480 \mathrm{~g}+\mathrm{TOT}$ & $4,13 \mathrm{ab}$ & $14,96 \mathrm{~b}$ & 53,35 \\
\hline Amonium glufosinat $640 \mathrm{~g}+\mathrm{TOT}$ & 6,80 & 3,45 bc & 3,40 \\
\hline Amonium glufosinat $800 \mathrm{~g}+\mathrm{TOT}$ & 7,62 & 1,25 & 4,05 \\
\hline Amonium glufosinat $960 \mathrm{~g}+\mathrm{TOT}$ & $2,17 \quad a b$ & 0,72 & 0,00 \\
\hline Mekanis + OTS & $0,00 \quad b$ & $0,00 \quad \mathrm{c}$ & 0,00 \\
\hline Kontrol & $16,77 \mathrm{a}$ & 39,03 a & 117,43 a \\
\hline BNT 0,05 & 14,96 & 14,55 & 41,11 \\
\hline
\end{tabular}

Keterangan: Nilai tengah pada setiap kolom yang diikuti huruf yang sama tidak berbeda nyata menurut uji BNT pada taraf $5 \%$

Tabel 9. Hasil Gabah Kering Giling

\begin{tabular}{lc}
\hline Perlakuan & GKG \\
& $(\mathrm{t} / \mathrm{ha})$ \\
\hline Amonium glufosinat $480 \mathrm{~g}+$ TOT & $0,90 \mathrm{c}$ \\
Amonium glufosinat $640 \mathrm{~g}+$ TOT & $2,31 \mathrm{~b}$ \\
Amonium glufosinat $800 \mathrm{~g}+$ TOT & $3,18 \mathrm{~b}$ \\
Amonium glufosinat $960 \mathrm{~g}+$ TOT & $2,71 \mathrm{~b}$ \\
Mekanis + OTS & $9,98 \mathrm{a}$ \\
Kontrol & $0,12 \mathrm{c}$ \\
\hline BNT 0,05 & 1,3 \\
\hline
\end{tabular}

Keterangan: Nilai tengah pada setiap kolom yang diikuti huruf yang sama tidak berbeda nyata menurut uji BNT pada taraf $5 \%$

5, Tabel 6, dan Tabel 8). Pada 7 MSA perlakuan mekanis dengan sistem ORS memiliki daya kendali yang sama dengan perlakuan herbisida amonium glufosinat dosis 960g/ha (Tabel 2, Tabel 4, Tabel 7, dan Tabel 8). Bahkan pada Tabel 1 dan 6 perlakuan mekanis dengan sistem OTS memberikan hasil yang terbaik di 7 MSA. Pengendalian gulma pada sistem TOT dilakukan satu kali pada satu minggu sebelum tanam. Sedangkan pengendalian gulma dengan sistem OTS dilakukan sebanyak 4 kali yaitu pada saat pengolahan lahan dan penyiangan mekanis yang dilakukan $3 \mathrm{kali}$, sehingga membutuhkan lebih banyak tenaga kerja.

Perlakuan herbisida amonium glufosinat dosis 480 $\mathrm{g} /$ ha memberikan hasil gabah kering giling yang tidak berbeda nyata dengan kontrol, sedangkan perlakuan herbisida amonium glufosinat dosis 640"960 g/ha memberikan hasil gabah kering giling yang lebih baik dibandingkan dengan kontrol. Namun hasil gabah kering giling terbaik adalah pada perlakuan mekanis dengan sistem OTS (Tabel 9). Menurut Marpaung et al., (2013), kerugian yang disebabkan oleh gulma memiliki hubungan antara waktu kemunculan gulma dan tekanan yang diberikan tanaman. Kehilangan hasil biasanya lebih tinggi ketika gulma muncul pada awal pertumbuhan. Gulma sudah ada pada petak perlakuan dengan sistem TOT saat tanam pindah sehingga memberikan tekanan yang tinggi pada tanaman, maka memberikan hasil gabah kering giling yang rendah.

\section{KESIMPULAN}

Kesimpulan yang diperoleh dari penelitian yang telah dilakukan adalah semua taraf dosis herbisida amonium glufosinat yang diuji (480-960 g/ha) dan penyiangan mekanis mampu mengendalikan gulma total dan gulma golongan rumput hingga 7 minggu setelah aplikasi (MSA), sedangkan gulma golongan daun lebar dan golongan rumput mampu dikendalikan oleh herbisida 
amonium glufosinat pada taraf dosis 640-960 g/ha dan penyiangan mekanis hingga 7 MSA, namun gulma golongan teki terutama Fimbristilys miliacea serta gulma Leptochloa chinensis tidak mampu dikendalikan oleh herbisida ini. Hasil gabah kering giling pada sistem TOT lebih rendah dibandingkan dengan hasil gabah kering giling jika pada sistem OTS.

\section{DAFTAR PUSTAKA}

Gupta, O.P. 1984. Scientific Management. Today and Tomorrows Printers and Pub. New Delhi India. $474 \mathrm{hlm}$.

Kropff, M.J. dan H. H. van Laar. 1993. Modelling Crop- Weed Interactions. CAB International. Great Britain. $274 \mathrm{hlm}$.

Direktorat Jenderal Tanaman Pangan. 2014. Laporan Tahunan Direktorat Jenderal Tanaman Pangan 2013. Kementrian Pertanian RI. Jakarta. 247 hlm.

Marpaung, I.S., Y. Parto, dan E. Sodikin. 2013. Evaluasi Kerapatan Tanam dan Meteode Pengendalian Gulma pada Budidaya Padi Tanam Benih Langsung di Lahan Sawah Pasang Surut. Jurnal Lahan Suboptimal 2(1):93-99.

Moenandir, J. 1988. Persaingan Tanaman Budidaya dengan Gulma. CV Rajawali. Jakarta. 101 hlm.
Perkins, G.R. 1990. Proceedings of the $9^{\text {th }}$ Australian Weed Conference. Adelaide, South Australia. Hlm 544-7.

Rafiuddin, R. Padjung, dan M. Tandi. 2006. Efek Sistem Olah Tanah dan Super Mikro Hayati terhadap Pertumbuhan dan Produksi Jagung. Jurnal Agrivor 5 (3) : 2-6.

Sembodo, D. R. J. 2010. Gulma dan Pengelolaannya. Graha Ilmu. Yogyakarta. $166 \mathrm{hlm}$.

Suardi, D. dan H. Pane. 1983. Daya Saing Beberapa Varietas Padi terhadap Gulma. J. Penelitian dan Pengembangan Pertanian (III): 63-66.

Tjitrosoedirdjo, S., I. H. Utomo,dan J. Wiroatmodjo (Eds). 1984. Pengelolaan Gulma di Perkebunan. Kerjasama Biotrop Bogor - PT. Gramedia. Jakarta. $225 \mathrm{hlm}$.

Utomo, M. 2002. Olah tanah konservasi untuk pengelolaan lahan berkelanjutan. Dalam: S. Hardiastuti, E. K., E. M. Nirmala, Lagiman, D. Kastono, S. Virgawati\& A. W. Rizain (eds.) Prosiding Seminar Nasional Budidaya Olah Tanah Konservasi. Yogyakarta, 30 Juli 2002. hal. III:1-35. 